\title{
AN ANALYSIS OF BACKCOUNTRY ACCIDENTS AND Rescue in Grand Teton National Park
}

\author{
GEORGE MONTOPOLI $\downarrow$ DEPARTMENT OF STATISTICS \\ KEN GEROW $\downarrow$ DEPARTMENT OF ZOOLOGY/PHYSIOLOGY \\ UNIVERSITY OF WYOMING $\downarrow$ LARAMIE
}

\begin{abstract}
$\downarrow \quad$ ABSTRACT
Since 1950, detailed records of all climbing accidents in Grand Teton National Park were maintained by rangers (and others) involved in rescue. In this paper, we present: 1) an overall summary of backcountry accidents, their locations, and causes since $1950 ; 2$ ) several summaries of the accidents by decades, locations and activity levels; 3) a fatality synopsis; and 4) an in-depth overview of the current accident trend from 1994 through 1996, which includes a male and female accident profile, cause and location summary, cost analysis, and other information.
\end{abstract}

From 1950 through 1996, 609 significant backcountry accidents have occurred, resulting in an average of about 13 incidents per year. The two categories involving the greatest number of accidents include Fall on Rocks (195) and Fall on Snow (155). Most accidents occurred during the 1970 's, and are currently on the decline. Accidents caused by Rockfall or Icefall were most prevalent in the 1960 's, indicating that perhaps many of the popular routes were "cleaned" during this time period. From 1950 through the 1970 's, the accident rate, when scaled for activity level during the decades, increased. Since the 1970 's, the rate has decreased to a low in the 1990's (0.22\%). The overall scaled accident rate for the period from 1950 through 1996 was $0.31 \%$.
The vast majority of climbing accidents occur in the Central and Northern climbing areas. In the Central Climbing area, the Grand Teton has the greatest number of incidents (121), followed by Disappointment Peak (39), Middle Teton (38), and Teewinot Mountain (32). In the Northern Climbing area, Symmetry Spire exhibits the greatest number of accidents (39). When examined by decades after being scaled for decade activity, a decline in the number of accident incidents for the 1990's is displayed in nearly all locations. One exception is Albright Peak in the Southern Climbing area, which shows a steady increase in incidents over the decades. Although the Grand Teton has experienced the greatest number of climbing accidents, the relative number of incidents is low when scaled for climbing level. Interestingly, Storm Point and Symmetry Spire in the Northern Climbing area actually exhibit the greatest number of incidents when backcountry activity is taken into account. Cascade Canyon receives the greatest number of non-climbing incidents, both in actual numbers and when scaled for backcountry activity. Most fatalities in the Tetons result from unroped falls from rock that occur while ascending and descending routes.

The current accident trend (1994-1996) indicates that falls on snow are the most prevalent cause of accidents, followed by falls on rock. The Grand Teton and Middle Teton have the greatest number of climbing accidents, but when scaled for climbing activity, Storm Point and Mt. Owen have 
the greatest number of accidents. Cascade Canyon has the greatest number of non-climbing accidents, but when scaled for backcountry activity, Garnet Canyon demonstrates the greatest number of accidents. Most women who experience accidents in the Tetons suffer from falls on snow, have an average age of 29.7 years, and almost always fall during the descent. Most men who experience accidents in the Tetons suffer from falls on snow, and have an average age of 35.7. Fifty-seven percent of men who experience accidents on climbing trips also fall during the descent. Two accidents involving only men were situations associated with getting stuck and falls during rappel. Most accidents are currently reported by people from other parties; however, $25 \%$ of the reports come from backcountry rangers in the field. The use of cell phones to report accidents has grown dramatically. Recently, there has been an average of 119 incidents per year involving some form of rescue response, at an average annual cost of $\$ 73,215.21$.

\section{ACKNOWLEDGMENTS}

This research was made possible through funding from the University of Wyoming-National Park Service Research Grant Program. We therefore extend our deepest gratitude to this agency, and in particular, to Dr. Hank Harlow, the Director of the UW-NPS Research Program.

In addition, for assistance with this project and for contributing to the successful collection of information, we extend our gratitude to Grand Teton National Park Service personnel, both past and present, whose efforts have resulted in many happy endings to serious accidents in the Teton Range.

\section{INTRODUCTION}

On August 4, 1925, after a successful ascent of the Grand Teton, Theodore Teepe slid to his death while descending the glacier that now bears his name. This event became the first documented climbing accident in an area that evolved into one of the premier mountaineering ranges in the contiguous United States during the Twentieth Century. Prior to 1950, few accident incidents were recorded, most likely due to the fact that recreational activities were a low priority in a country experiencing a depression and world wars. Backcountry excursions increased in frequency after the second world war, and details of all climbing incidents in Grand Teton National Park were maintained by those rangers (and others) involved in the consequent rescues and body recoveries, starting in 1950.

In this paper, we present: 1) an overall summary of backcountry accidents, their locations, and causes since 1950; 2) several summaries of the accidents by decades, locations and activity levels; 3) a fatality synopsis; and 4) an in-depth overview of the current accident trend from 1994 through 1996, which includes a male and female accident profile, cause and location summary, cost analysis, and other information.

\section{DEFINITION OF TERMS}

The backcountry incidents analyzed in this paper include backpacking, climbing, hiking, and backcountry skiing activities. Excluded are accidents resulting from vehicles such as bicycles, boats, motor vehicles, planes, rafts, and snowmobiles, as well as horse and hunting incidents. Incidents concerning overdue parties that resulted in a rescue initiation but involved no injury or physical compromise to any individuals also have been excluded.

Accident incidents are defined according to the following categories:

- Climbing Injury: any (non-falling) physical injury sustained in the act of climbing, such as a dislocated shoulder or knee;

- Fall Hiking: any fall occurring while hiking on ground or snow that does not involve climbing;

- Fall on Rock: any fall that occurs while ascending or descending rock;

- Fall on Rappel: any fall that results while a person is descending a rope;

- Fall on Snow: any fall that occurs while ascending or descending snow or ice;

- Fall in Avalanche: any fall on snow that is caused by, or results in, an avalanche;

- Fall Skiing: any fall that occurs during a backcountry skiing trip, including technical mountain skiing attempts;

- Illness: any physiological compromise experienced by an individual in the backcountry, including altitude-related illnesses (e.g., Acute Mountain Sickness), myocardial 
infarction, hypothermia, dehydration, and burns;

- Lightning: any injury that can be attributed to lightning;

- Stuck: any situation where an individual is unable to progress under their own power, while ascending or descending, usually resulting from poor decision making;

- Rockfall or Icefall: any injury caused by rockfall or icefall that impacts an individual from above;

- Unknown: any incident with insufficient details; and

- Other: any incident that rarely occurs and that does not fit into any of the above categories, such as a fall with limited details, a fall during a rescue by a team member, a fall from a tree, or a lost individual.

\section{ACCIDENTS FROM 1950 THROUGH 1996}

\section{An Overview}

From 1950 through 1996, 609 significant backcountry accidents have occurred, resulting in an average of about 13 incidents per year. Figure 1 details these accidents by categories. The two categories involving the greatest number of accidents include Fall on Rock (195) and Fall on Snow (155), followed by Fall Hiking (74), Illness (56) and Rockfall or Icefall (41).

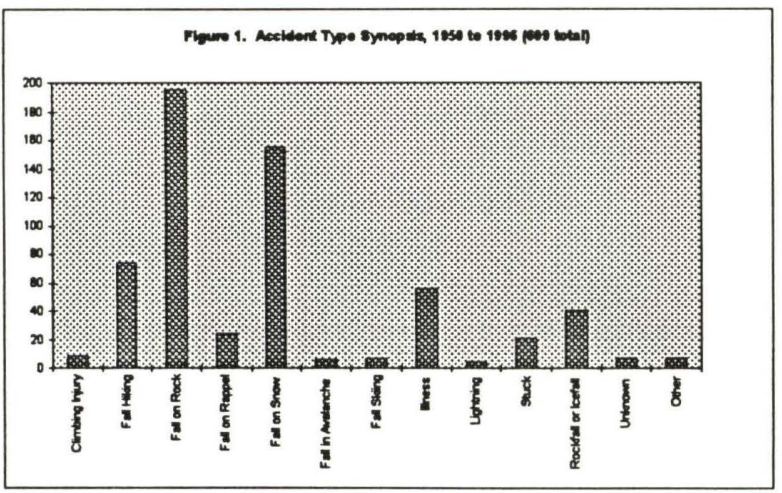

\section{A Synopsis by Decades}

To further investigate these incidents, accidents were analyzed by decade, by scaling the actual numbers according to backcountry activity during each decade, based on information estimated from Grand Teton National Park records. Numbers were scaled to account for backcountry intensity during each decade to better represent the actual trend. For example, if there were only 10 incidents during the 1960 's and 100 incidents during the 1970's, one would be alarmed by the ten-fold increase in incidents. However, if only 15 people ventured into the backcountry during the 1960 's, as compared to 1,000 in the 1970's, the incident level for the 1960's would represent a more alarming situation. The results of the synopsis by decade are displayed in Figure2.

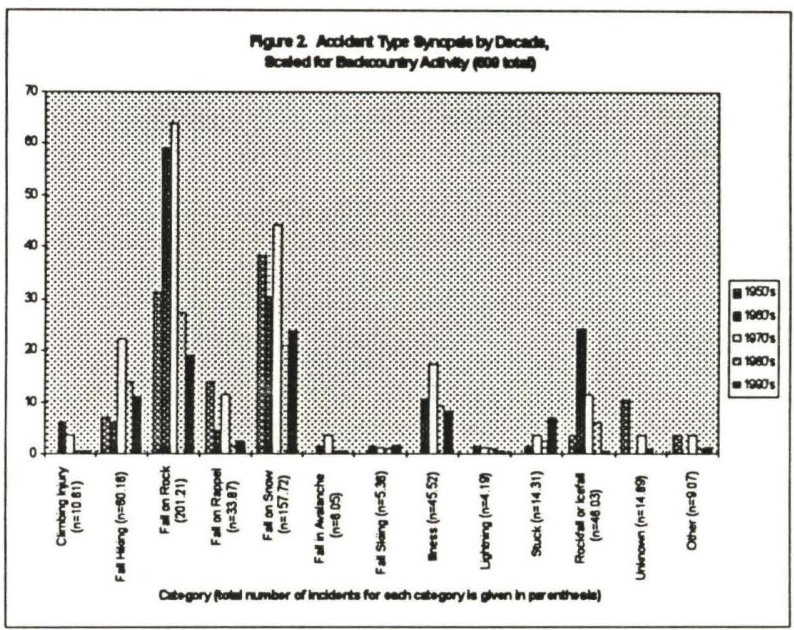

Several important observations are noted in Figure 2. The highest accident rates generally occurred during the 1970's, especially for the categories which resulted in most accidents, Fall on Rock and Fall on Snow. Accidents caused by Rockfall or Icefall were most prevalent in the 1960 's, indicating that perhaps many of the popular routes were "cleaned" during this time period. Relative to the 1960's and 1970's, accident rates generally have decreased in the 1990's, except for the Stuck category, where the number of incidents has significantly increased. This current trend may suggest that climbers with minimal mountain experience are becoming more bold and less prudent, sometimes as a result of assuming that a rescue team is "on standby" in the valley. Some attention should also be given the category Illness, which constitutes a high number of backcountry incidents. Illnesses in the backcountry often have dire consequences (with a fatality rate of $16 \%$ ).

Figure 3 demonstrates the accident rates over the decades, scaled for backcounty activity. As displayed in the figure, from 1950 though the 
1970 's, the scaled accident rate has increased. Since the 1970 's, the rate has decreased to a low in the 1990 's $(0.22 \%)$. The overall scaled accident rate for the period from 1950 through 1996 was $0.31 \%$.

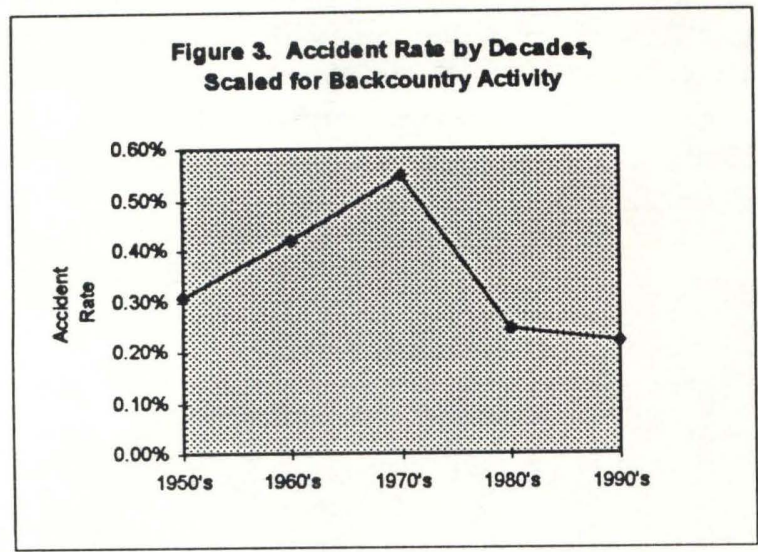

\section{A Look at Climbing Versus Non-Climbing Areas}

Another component of interest is to consider accident incidents in climbing areas (peaks and popular rock routes) separate from non-climbing areas (canyons and lake regions). Figure 4 demonstrates the total (unscaled) number of climbing incidents by location from 1950 through 1996.
For the period 1950 through 1996, most accidents have occurred in the Central Climbing Area, which includes the Grand Teton (121), Disappointment Peak ((39), Middle Teton (38), Teewinot (32), and Mt. Owen (19). In the Northern Climbing Area, most accidents have occurred at Symmetry Spire (39), followed by Mt. Moran (20), the Exum Practice Rocks (15), Baxter's Pinnacle (14), and Storm Point (13). The elevated occurrence of accidents in these locations may be due to the high number of people that frequent them: the Central Climbing Area contains the high, challenging mountain peaks that most people who visit the range attempt to climb; the Northern Climbing Area contains Mt. Moran that draws attention because of its many challenging routes, while the other noted locations are relatively accessible and are climbed as conditioning exercises by many individuals.

When scaled to account for climbing activity during each decade, the vast majority of accidents continue to occur in the Central and Northern climbing areas, with relatively few accidents occurring in the Southern Climbing Area. The five areas that experienced the most accidents are the Grand Teton (114.01), Symmetry Spire (48.24), Teewinot (45.45), Disappointment Peak (37.81), and Middle Teton (28.31). Note that

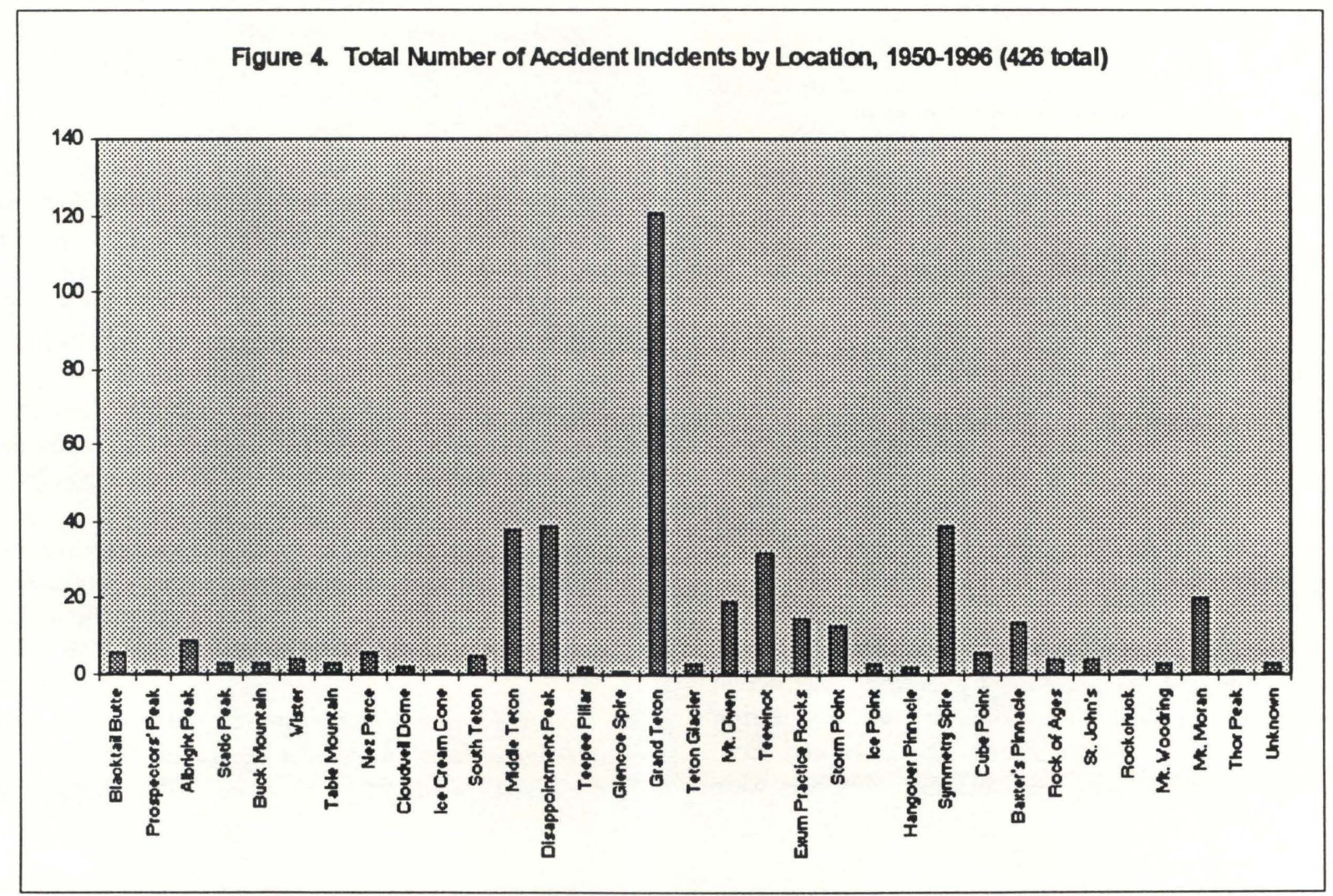


Symmetry Spire from the Northern Climbing Area experiences the second greatest number of accident incidents in the Teton Range when accidents incidents are scaled for climbing activity during the decades.

Another interesting observation is that a decline in the number of accident incidents for the 1990 's is displayed in nearly all locations. One exception is Albright Peak in the Southern Climbing area, which shows a steady increase in incidents over the decades. This peak contains some of the more difficult rock routes in the Teton Range, many of which have only recently been completed (and have yet to be cleaned). Hence, with recent interest generated for climbing the difficult routes in this area, an increase in the number of accident incidents should be anticipated in the future. This may be due to standards of climbing being pushed with new routes, climbers pushing their individual limits, and/or the routes being cleaned of loose debris.

Other climbing locations demonstrate various accident profiles. For instance, Middle Teton shows a somewhat constant number of accident incidents, while Disappointment Peak shows a greater number of incidents during the 1970's. While Mt. Owen, the Exum Practice Rocks, and Storm Point display similar profiles, Teewinot Mountain displays a greater number of accident incidents in the 1950's, with a stair-step decline during each subsequent decade.

Figure 5 examines the accident incidents from another perspective. Nine areas where accidents most frequently occurred were scaled for climbing activity specific to those areas for which data were available, during the entire time period 1950-1996. For example, the Grand Teton has experienced 121 accident incidents since 1950, but it also has received the most attention with respect to numbers of individuals attempting the mountain. This situation is accounted for by scaling for climbing activity specific to the areas.

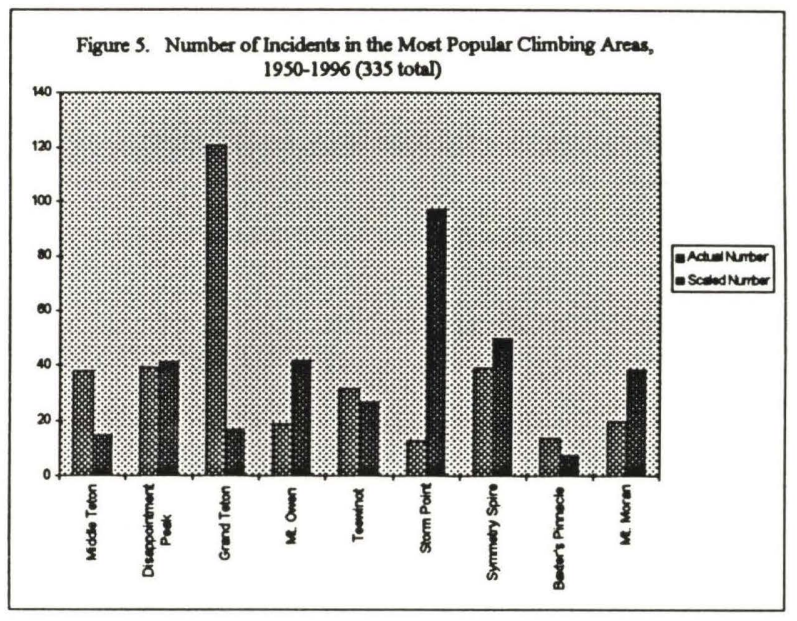

As indicated in Figure 5, although the Grand Teton has experienced the greatest number of accident incidents, the relative number of accident incidents is low when scaled for activity level. Interestingly, Storm Point and Symmetry Spire in the Northern Climbing area actually exhibit the greatest number of accident incidents when activity is taken into account. The marked increase in number of accidents when scaled for activity (as compared to not being scaled) demonstrated by Storm Point, Mt. Owen, Mt. Moran, and Symmetry Spire indicates that these locations may be particularly dangerous.

Non-climbing accident incidents were also investigated by examining canyons and lake areas. Figure 6 shows the total (unscaled) number of backcountry incidents in canyons from 1950 through 1996.

As indicated in figure 6, Cascade Canyon experienced the greatest number of non-climbing incidents, followed by Paintbrush Canyon, Garnet Canyon, and Granite Canyon. This arrangement occured both for the actual number of incidents and when incident numbers were scaled for activity during each decade, suggesting that more accidents occur with greater number of individuals, regardless of the decade. Finally, most non-climbing backcountry incidents occurred in the 1970's. 


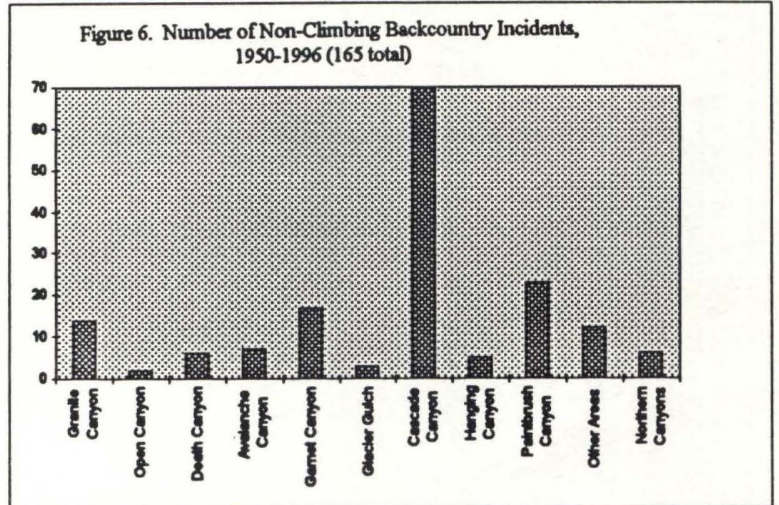

Other Areas = Alaska Basin, Stewart Draw, Surprise Lake Trail, Vahalla Canyon, Valley Trail, and Whitegrass Road Northern Canyons = Leigh Canyon, Moose Basin, Moran Canyon, Owl Canyon, and Waterfall Canyon

Figure 7 depicts the accident incidents from another perspective. Seven non-climbing areas where accidents most frequently occurred were scaled for backcountry activity specific to those areas for which data were available, during the entire time period from 1950 through 1996. For example, Cascade Canyon experienced 120 accident incidents since 1950, but it also received the most attention with respect to numbers of individuals (about 1000 people per day). This situation is accounted for by scaling for backcountry activity specific to the areas.

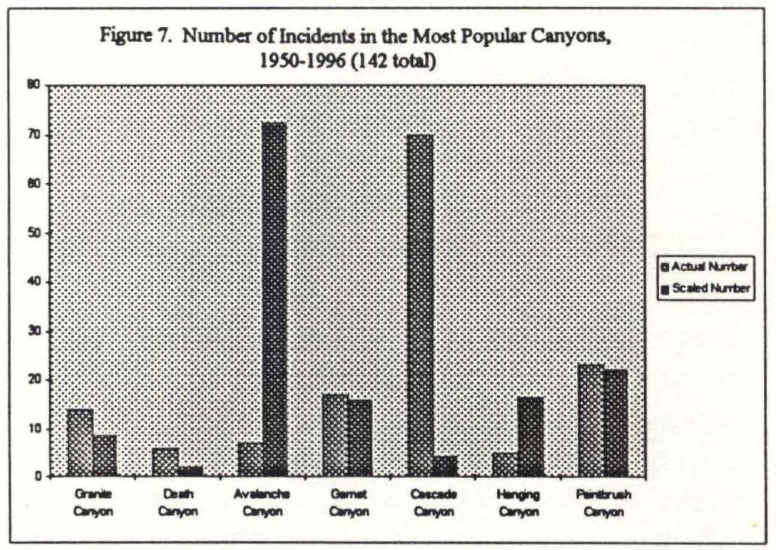

Figure 7 shows that most accidents occurred in Avalanche Canyon, when backcountry activity is taken into account. Avalanche Canyon was followed by Paintbrush Canyon, Hanging Canyon, and Garnet Canyon. Interestingly, Avalanche Canyon is a remote canyon lacking a maintained trail, which suggests that although few people visit the canyon, there is a relatively high chance that they will experience an accident. In the case of Cascade Canyon, the high number of accident incidents (70) is diluted by the high volume of people in that area.

Lake areas were also examined for number of non-climbing accident incidents during the decades. The lake areas, including Bearpaw, Bradley, Grizzly Bear, Iceflow, Jackson, Jenny, Leigh, Marion, Phelps, Surprise, Taggart, and Trapper Lakes, experienced few accident incidents during the decades. Most accidents occurred at Jenny Lake, where 5 incidents occurred, all in the 1980's. The other lakes each experienced one accident incident from 1950 through 1996, except for Leigh Lake which experienced two. Two incidents resulted in fatalities (at Jackson and Leigh Lakes), while those at Jenny Lake resulted from illness or falls while hiking around the lake. As stated previously, only backcountry accidents (no boating or horseback riding accidents) were included in this analysis.

\section{FATALITY SYNOPSIS, 1950-1996}

From 1950 through 1996, ninety fatalities occurred in the backcountry of Grand Teton National Park, resulting in an average of about 2 fatalities per year. Figure 8 demonstrates the categories which comprised the fatalities.

As indicated in the figure 8, falls on rock and on snow resulted in the greatest number of fatalities, followed by avalanches, illnesses, and falls during rappel.

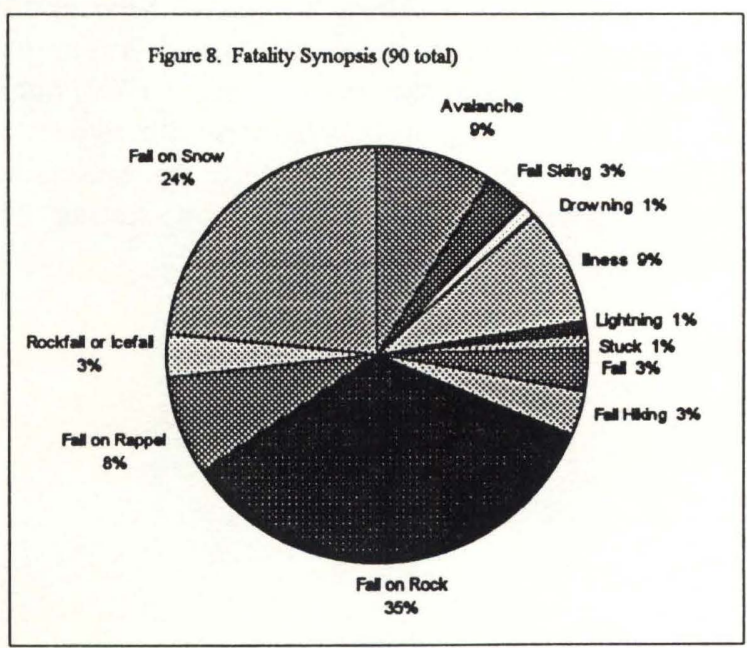


Most people who died from falls on rock are unroped. While $27 \%$ fell and died while ascending unroped, $22 \%$ fell and died while descending unroped. Of those individuals that were roped and ascending on rock, $24 \%$ fell and died while leading. Finally, $18 \%$ of the people that fell on rock and died did so because of anchor failure during rappel. Unfortunately, many of these fatalities were the result of exhaustion and/or poor judgment by those that were involved.

Figure 9 shows fatality rates associated with the various accident codes. As demonstrated in the figure, $100 \%$ of those people involved in avalanches perished. Other activities that have high fatality rates associated with them include skiing, rappelling, lightning, falls on rock, illness, and falls on snow.

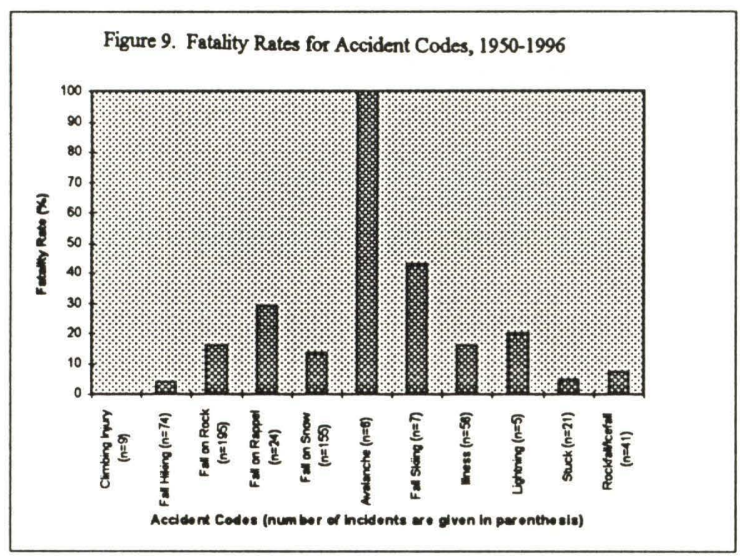

\section{AN ANALYSIS OF CURRENT ACCIDENT PATTERNS (1994-1996)}

One of the main purposes of the analysis is to give useful information to backcountry users (climbers and hikers) and rescue personnel that will aid in reducing the number and severity of accidents (or at least reduce the rate, since as backcountry use increases, the number of accidents tend to increase). This section of the report focuses on current trends (1994-1996) with prevention of future accidents in mind.

Over the years, the accident rate among climbers is about $0.31 \%$ or about 3 incidents per 1000 climbing attempts. Currently, the Tetons experience approximately 10,000 climbing attempts per season, which suggests, on average, that we might expect 30 incidents per season. While the rate is low, 30 accidents is still a large number per season.

\section{Accident Categories from 1994 through 1996}

Figure 10 indicates that currently most accidents result from falls on snow, followed by falls on rock. Interestingly, during the 1960's, 1970's, and 1980's, most accidents were caused by falls on rock, with falls on snow following. Only during the 1950's was the current trend exhibited. Although difficult to prove, this may suggest that climate (such as heavy snowfall years) may play a role in determining the most prevalent type of accident.

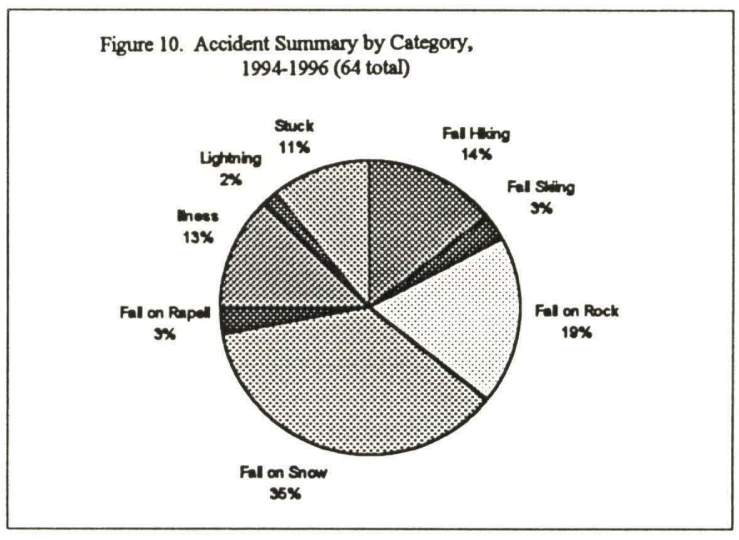

If we combine this information with the fact that $80 \%$ of accidents occur after noon and $66 \%$ percent of accidents occur on the descent, then the falls on snow may likely be attributable to fatigue (caused by a combination of exertion and dehydration), with weather, snow conditions, and inexperience on snow adding to the problem. Thus, as regards safety points to be made from the current accident trend, the obvious has been highlighted by the type and timing of accidents: on descents, especially on snow, climbers are often tired, dehydrated, and, perhaps, too relaxed and unaware of the dangers inherent to snow (all the "hard" stuff having been done earlier in the day).

\section{Climbing Versus Non-Climbing Areas}

Figure 11 displays the number of climbing accidents from 1994 through 1996 in climbing areas where they occurred. Both the actual number and 
the number scaled for climbing activity are shown for each area. Although the Grand Teton and Middle Teton experienced the greatest number of accident incidents, when climbing activity in each area was taken into account, Storm Point, Albright Peak, Mt. Owen, Disappointment Peak, and Mt. Moran demonstrated the greatest number of scaled incidents. In addition, these areas along with Symmetry Spire and South Teton each demonstrated a greater number of scaled incidents when compared to unscaled incidents, indicating that these locations may be more dangerous than other locations (where this trend is not exhibited). Static Peak did not have a scaled value associated with it because data were available.

As mentioned previously, Albright Peak contains some of the more difficult rock routes in the Tetons, and an increase in accident incidents should be anticipated in the future if an increase in climbing activity in that area occurs (due to current trends that involve climbing difficult rock routes).

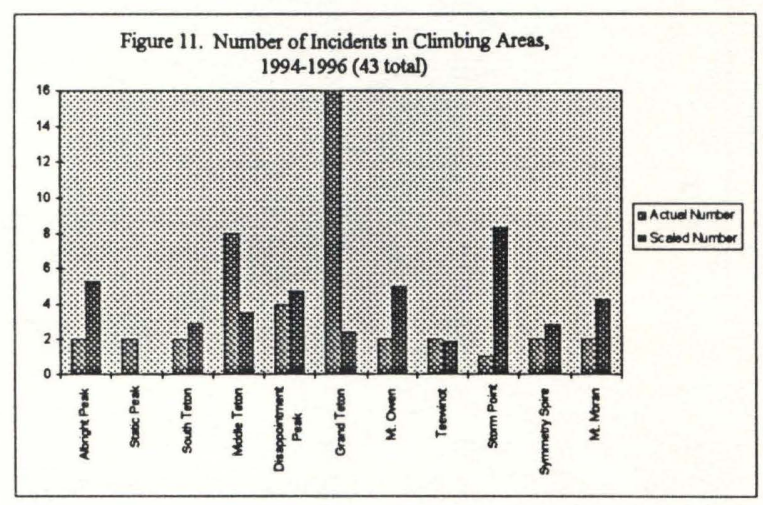

Figure 12 shows the number of nonclimbing accidents from 1994 through 1996 in the locations where they occurred. Both the actual number and a number scaled for backcountry activity are displayed for each location. Although Cascade Canyon has experienced the greatest number of incidents, when scaled for backcountry activity, Garnet Canyon, Paintbrush Canyon, and Granite Canyon demonstrated the greatest number of relative incidents. Garnet Canyon appeared to be particularly dangerous due to the large increase in scaled incidents when compared to unscaled incidents. Glacier Gulch did not have a scaled value associated with it due to a lack of available data.

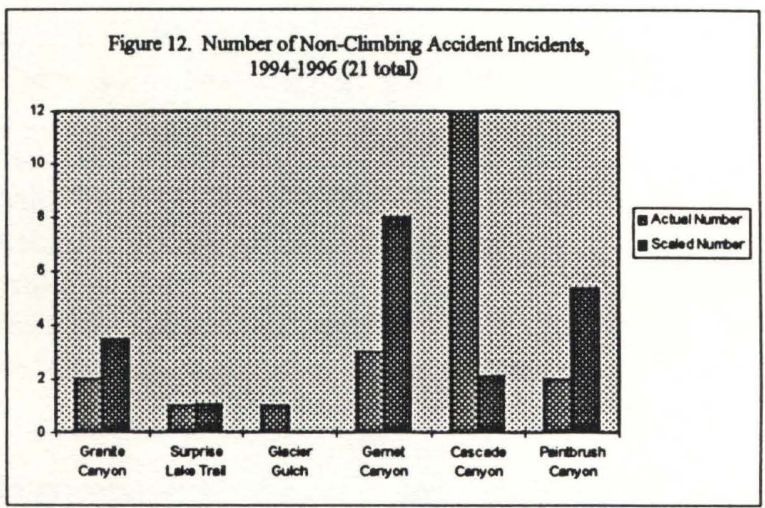

\section{A Gender Accident Profile}

Figure 13 shows a breakdown of accidents by category and gender. Assuming that illness strikes both genders equally frequently, the Illness category serves as an approximation for the relative numbers of male to female backcountry users; that is, males outnumber females approximately 6 to 1 (for instance, the Fall Skiing category roughly maintains that proportion). If the gender of a person makes no difference in the type of accident that is experienced, then the other accident categories should reflect the same 6 to 1 ratio of males to females (it is difficult to make useful inferences without taking into account proportions of males and females doing various activities in the backcountry). Based on this assumption, several comparisons may be made. For example, when compared to men, a disproportionately greater number of women suffer from falls while hiking, falls on rock, and falls on snow. When compared to women, a disproportionately greater number of men suffer from falls while rappelling and getting stuck.

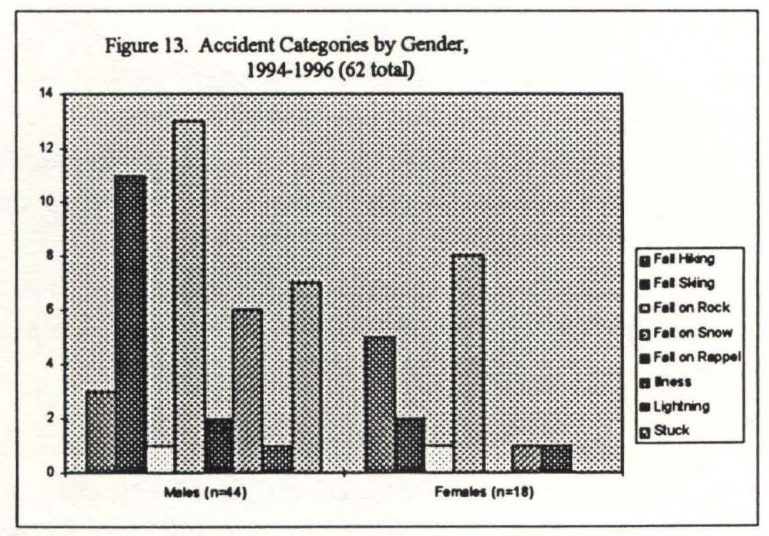




\section{The Female Accident Profile}

Figure 13 shows that most women who experience accidents in the backcountry suffer from falls on snow, followed by falls while hiking and while skiing. Ninety percent of women who suffer accidents on climbing trips fall during the descent. The age groups that experience the most accidents include teens, twenties, and forties, with an average age of 29.7 .

\section{The Male Accident Profile}

Figure 13 shows that most men who experience accidents in the backcountry suffer from falls on snow, followed by falls while skiing, getting stuck (unable to proceed up or down), and illness. Fifty-seven percent of men who suffer accidents on climbing trips fall during the descent. The age groups that experience the most accidents include the twenties and thirties, with an average age of 35.7.

Two categories in which only men were injured include Stuck and Fall on Rappel. For the most part, falling on rappel and getting stuck seem to be relatively pure judgment-derived accidents. While the numbers are low (two males falling on rappel, and seven males getting stuck), one can only speculate as to why these accidents have all happened to men.

\section{How Accidents are Currently Reported}

Direct communication from rangers in the backcountry and ranger-initiated overdue checks accounted for approximately $25 \%$ of accidents being reported, highlighting the importance of backcountry rangers and patrols. The affected climbing party (either the victim or a partner) accounted for about another $25 \%$, while people from other parties (hikers or climbers) reported almost $50 \%$. One positive consequence of increased backcountry activity is that accidents may get reported more quickly, and thus attended to more efficaciously.

Interestingly, $17 \%$ of accidents were reported via cellular telephones (most of these were from climbing guides). This will likely increase in the future; whether it helps with the accident situation (speedier responses to incidents) or makes it worse (parties depending on the phone for backup may not be as conservative in critical judgment decisions) remain to be seen.

\section{Day of the Week}

The number of accident incidents according to day of the week was investigated to see if accidents occurred more frequently on certain days. Two points should be made: 1) although most incidents occurred on Saturday, this number is not significant in a statistical sense; that is, it did not deviate significantly from the expected number of about 9 incidents per day $\left(c^{2}=4.47, \mathrm{df}=6, \mathrm{p}=\right.$ 0.6135); and, 2) due to lack of data, it is not possible to scale the number of incidents according to activity level for each day (if more people were to venture out into the backcountry on Saturday, more incidents would be expected). However, the fact still remains that from 1994 through 1996 more incidents occurred on Saturday than on any other day, and fewest occurred on Monday.

\section{$\underline{\text { Cost Summary }}$}

Table 1 presents a yearly cost summary for the period 1994 through 1996, based on all backcountry incidents where a rescue response was initiated whether it was warranted or not. Although insignificant incidents (those that were unfounded, or involved no physical injury or compromise to anyone such as overdue parties) were not included in the previous analysis, they were included in this cost summary because their only consequence was an associated cost resulting from the initiation of a rescue response.

Table 24. Cost Summary, 1994-1996
\begin{tabular}{|c|c|c|c|c|}
\hline & $\begin{array}{c}\text { Number of } \\
\text { Incidents }\end{array}$ & $\begin{array}{c}\text { Number of } \\
\text { Subjects }\end{array}$ & $\begin{array}{c}\text { Number of } \\
\text { Lives Saved }\end{array}$ & Cost \\
\hline 1994 & 107 & 126 & 4 & $\$ 58,098.00$ \\
\hline 1995 & 102 & 125 & 5 & $\$ 65,262.79$ \\
\hline 1996 & 148 & 269 & 7 & $\$ 96,284.84$ \\
\hline Total & 357 & 520 & 16 & $\$ 219,645.63$ \\
\hline
\end{tabular}

The total cost of rescue for the period 1994 through 1996 was $\$ 219,645.63$. Although the cost of a single rescue can drastically vary (in 1995, a single incident cost $\$ 18,463$ ), when the total cost of rescue was averaged by the number of incidents, each rescue response had an associated cost of $\$ 615.25$. The three-year average cost for all rescue responses was \$73,215.21 per year, with an average of about 119 incidents per year involving 173 individuals per year. 


\section{SUMMARY COMMENTS}

In this paper, we have presented information that is interesting from a historical perspective. More importantly, the information may be useful for the prevention of future accidents and injury, especially when examining current trends. Locations have been identified that present high accident risk, especially those that demonstrate a greater number of accidents when scaled for activity level and compared to the actual number that occur. Types of accidents that commonly occur and characteristics about these accidents have been described, as well as information about individuals involved in accidents.

With respect to prevention, educational effort should be directed to those areas for the specific activities that are involved, with emphasis placed on the causes of the accidents that occur. Grand Teton National Park personnel are currently engaged in educational activities that should be continued, even possibly expanded. For example, seminars are offered to concession workers and other groups, information is freely dispersed to the public at ranger stations, and technical mountaineering issues are addressed at Jenny Lake
Ranger Station. In addition, displays that educate people about accidents and their causes, where and when they most frequently occur, the individuals who are most frequently involved, and how to prevent them, would aid in prevention (one is under construction for the Jenny Lake Ranger Station as a result of this study).

Accidents will continue to occur. To minimize injury to the involved individuals, rapid response and evacuation of the injured to medical facilities are imperative. Current park efforts that are directed to accomplishing these actions should continue. For example, ranger patrols are frequently scheduled in areas where accidents often occur, a patrol/rescue hut is maintained on the Lower Saddle of the Grand Teton during the climbing season, and a helicopter rescue program has been implemented.

Certainly the cost of rescue is significant; however, in addition to ameliorating the injuries suffered by individuals and in many situations preventing more serious complications from evolving, the lives of at least 16 individuals were spared as a result of the rescues. This fact by itself should justify the costs of any rescue effort. 